\title{
ICE SHEET ELEVATION MAPPING AND CHANGE DETECTION WITH THE ICE, CLOUD AND LAND ELEVATION SATELLITE-2
}

\author{
B. M. Csatho ${ }^{1, *}$, A. F. Schenk ${ }^{1}$, T. Neumann ${ }^{2}$ \\ ${ }^{1}$ Department of Earth Sciences, University at Buffalo, Buffalo, NY - (bcsatho, afschenk)@ buffalo.edu \\ ${ }^{2}$ NASA Goddard Space Flight Center, Greenbelt, MD - thomas.neumann@ nasa.gov
}

Commission III, WG III/9

KEY WORDS: Cryospheric research, Spaceborne LIDAR, Photon-counting LIDAR, Monitoring ice sheets

\begin{abstract}
:
On September 15, 2018, ICESat-2 (Ice, Cloud, and land Elevation satellite) was successfully launched to measure ice sheet and glacier elevation change, sea ice freeboard, and vegetation. This paper describes the computation of surface elevation change rates obtained with SERAC (Surface Elevation Reconstruction And Change detection) from ICESat-2 observations. After summarizing some relevant aspects of ICESat-2 and its sole instrument ATLAS (Advanced Topographic Laser Altimetry System) the paper focuses on how we calculate time series of elevation change rates from ICESat-2's data product ATL03. Since real ICESat-2 data suitable for generating time series of several time epochs are not yet available, we used simulated data for this study. We will start generating time series from real ICESat-2 data after the conclusion of the ongoing calibration and validation phase and we expect to present real-world examples at the WG III/9 meeting in June, 2019 in Enschede, The Netherlands.
\end{abstract}

\section{INTRODUCTION}

The response of the cryosphere to increasing global temperatures has crucial consequences for society. Predictions of the rate of sea level rise through the next century rely on accurate understanding and modeling of glacier and ice sheet behavior (Pattyn et al., 2018). Since the late 1990s observations have revealed dramatic changes of many ice streams and outlet glaciers in Greenland and Antarctica, causing alarming mass loss (Enderlin et al., 2014, van Den Broeke et al., 2016, The IMBIE team, 2018). Consequently, it is crucial to deepen our understanding of how the ice sheets may respond to future climate changes. To quantify surface elevation changes, investigate what causes them, and to improve predictive ice sheet models, it is imperative to monitor elevation changes on a seasonal, annual and inter-annual basis and at scales ranging from entire ice sheets to individual outlet glaciers.

NASA met the challenge of monitoring the polar ice sheets by launching laser altimetry missions aimed at collecting observations from which time series of surface elevation changes can be determined. On January 12, 2003, NASA launched Ice, Cloud, and land Elevation Satellite (ICESat), the first spaceborne laser altimetry mission with the primary goal to gather surface measurements of ice sheets, sea ice, and vegetation heights (Zwally et al., 2002). The satellite carried GLAS (Geoscience Laser Altimeter System), a single beam, analog waveform recording laser system. The system operated until 2009, putting an end to a most successful ICESat mission. During its lifetime of nearly seven years, ICESat produced global ice sheet and glacier surface elevation measurements with unprecedented accuracy.

Ice, Cloud, and land Elevation Satellite-2 (ICESat-2), the successor of ICESat, was launched on September 15, 2018. The near-polar orbit has an inclination of $92^{\circ}$, producing a coverage between $88^{\circ}$ north and south, with a 91-day exact

\footnotetext{
${ }^{*}$ Corresponding author
}

repeat cycle (Markus et al., 2017). ICESat-2 carries the ATLAS (Advanced Topographic Laser Altimeter System) instrument, the first photon-counting laser altimeter in space. The mission's primary goal is to monitor changes of land ice (ice sheet and glaciers) and sea ice thickness. Ultimately, the ATLAS observations will enable the estimation of ice-sheet and glacier mass balance and their contribution to sea level rise. The photon-counting laser technology and multi-beam solution of ATLAS are fundamentally different from the full-waveform, single beam GLAS system.

The purpose of this paper is to provide an overview of ICESat-2, including its mission goals, data products, and major applications, such as contributions to calibration and validation of ICESat-2, the calculation of time series of surface elevation changes, and the determination of the Earth's surface from original measurements of the photon cloud.

\section{BACKGROUND INFORMATION ABOUT ATLAS, THE PHOTON-COUNTING LASER ALTIMETER SYSTEM OF ICESAT-2}

Here we summarize the major principles of ATLAS, the single photon counting laser altimetry system carried on ICESat-2. It begins with generating a single, low-energy laser beam that will be split into six individual transmit beams by a diffractive optical element. Each beam illuminates a spot on the Earth's surface with a diameter of $\sim 14 \mathrm{~m}$. Fig. 1 shows five photons, labelled $P 1 \cdots P 5$. Some of the photons of a laser beam make it down to the ground $(\mathrm{P} 2, \mathrm{P} 4)$ where they are reflected into the entire hemisphere, assuming the illuminated spot is a Lambertian reflector. A miniscule amount of the reflected photons make it back through the telescope where they are detected and time-tagged by one of the photo-multiplier tubes (PMT), such as photon P2. Photon P4 is also reflected from the ground surface but into a direction outside the field of view (FOV) of the telescope. P1 is a photon that was reflected from a particle within the range window, just into the right 
direction of the FOV. This photon is detected and time-tagged as well. Photon P3 is scattered into a direction outside the FOV. There are also additional photons of the same wavelength but originating from different sources (e.g. sun) that might be reflected into the FOV and detected by the PMT (e.g. photon P5). The figure shows that out of the five photons three are detected but only $\mathrm{P} 2$ is truthfully reflected from the surface.

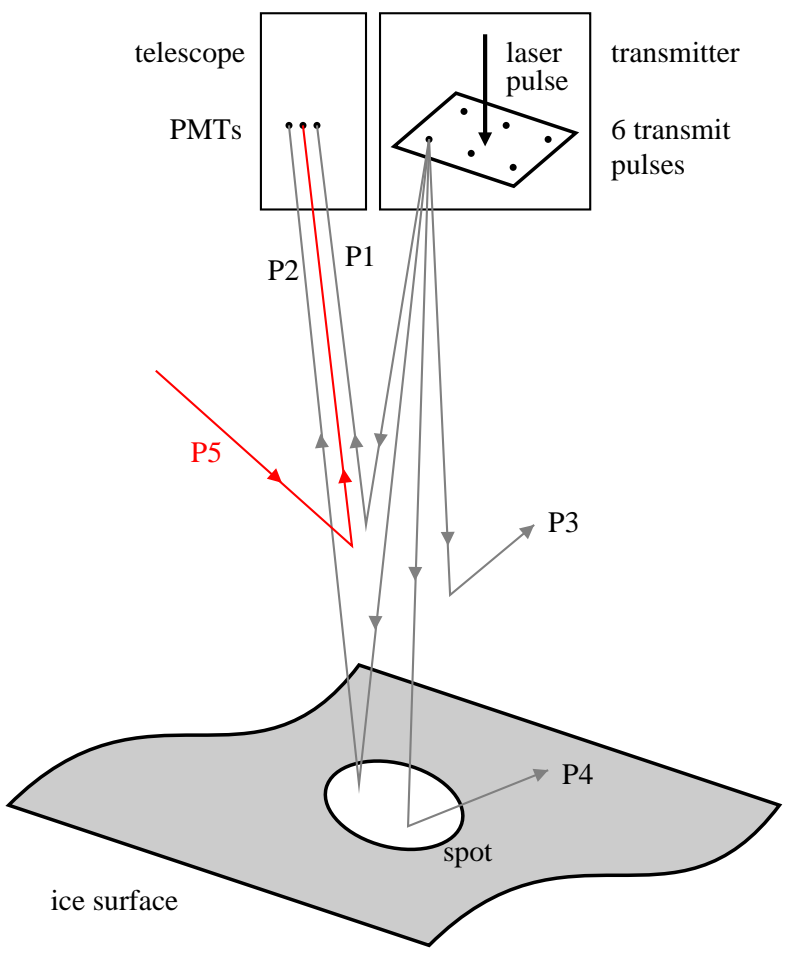

Figure 1: Sketch of single photon counting system of ATLAS. The original laser beam is split into six transmit beams and sent simultaneously to the ground where they illuminate a spot.

The six laser beams are arranged in three pairs: one central pair and two sideward looking pairs. The array with the six beams is slightly rotated with respect to the flight direction, causing the forward and backward beams of a pair to be separated by $\sim 90$ $\mathrm{m}$, enabling the determination of the across-track slope within a single time epoch and thus avoiding the correlation between cross slope and height changes that exists for one-beam profiling systems such as GLAS. The spot pairs are separated by $\sim 3.5 \mathrm{~km}$ across and by $\sim 2.5 \mathrm{~km}$ along the flight direction. Laser beams are emitted at a frequency of $10 \mathrm{kHz}$ and at a wavelength of $532 \mathrm{~nm}$. ICESat-2 orbits the earth at $\sim 500 \mathrm{~km}$ with a velocity of $\sim 7 \mathrm{~km} / \mathrm{s}$.

\section{APPLICATIONS}

Previous studies focusing on the development of surface extraction algorithms from ICESat-2 data used single photon-counting altimetry measurements from NASA's Multiple Altimeter Beam Experimental Lidar (MABEL) and Slope Imaging Multi-polarization Photon-counting Lidar (SIMPL) systems ((Herzfeld et al., 2017, Brunt et al., 2016). However, inclusion of single-photon laser altimetry data into a change detection algorithm requires ICESat-2 measurements extending existing altimetry time series. Such data sets are not available from MABEL and SIMPLE. Moreover, no real ICESat-2 data were available at the time of writing this paper.
Therefore, we used simulated data for this study. Simulated data were generated based on a DEM (Digital Elevation Model) spanning the lower trunk of Pine Island Glacier, West Antarctica (Schenk et al., submitted). The DEM was derived from a pair of high-resolution Worldview-2 optical images, acquired January 19, 2014, using the Ames Stereo Pipeline processing suite (Shean et al., 2016). The DEM is approximately $19 \mathrm{~km}$ wide, $110 \mathrm{~km}$ long, and is posted at 2.1 $\mathrm{m}$ in each direction.

\subsection{Determining the surface from the photon cloud}

ATL03 is the first ICESat-2 data product that contains geolocated coordinates for each photon event downlinked from ATLAS (Markus et al., 2017). In addition to geodetic latitude and longitude and ellipsoidal height, ancillary data are provided, such as land cover type and classification of photon events into signal photons (likely to have been reflected from the surface) and background photons (Neumann et al., submitted). This is as close as one can get to the original ATLAS observations because higher level data products are derivatives of the original photon cloud. Fig. 2 depicts two short along track segments of the downlinked photon cloud.

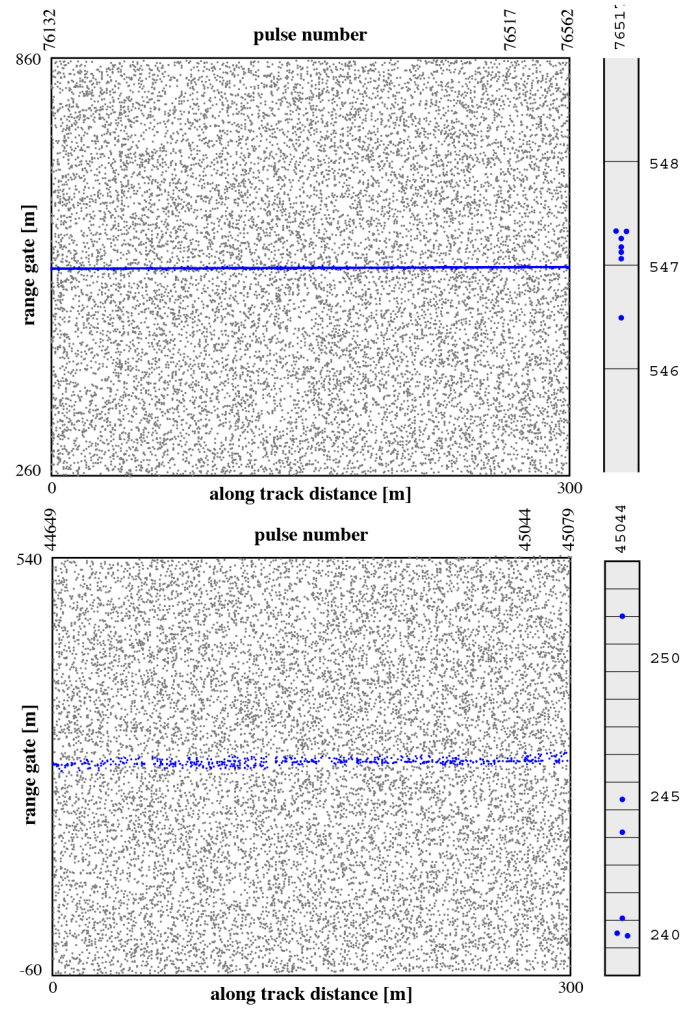

Figure 2: Shows $300 \mathrm{~m}$ long segments of two photon clouds. The gray dots are photon events and the blue dots represent signal photons. The upper panel depicts a photon cloud over relatively smooth ice, simulated under very favorable conditions (clear atmosphere, high surface reflectance). The lower panel is over very rugged ice, near the grounding line, simulated under marginal conditions. At the right side of each panel is shown an enlarged pulse with several signal photons. The main difference between the two examples is the spread of the signal photons (upper panel $\sim 1 \mathrm{~m}$, lower panel $\sim 12 \mathrm{~m}$ ). The lower panel also shows that there are many pulses without a single signal photon. 
The segments shown in Fig. 2 are $300 \mathrm{~m}$ long and contain about 428 pulses. The left panel shows a segment over relatively smooth ice while the right panel vividly demonstrates the difficulty to discern the surface over very rugged parts of the ice sheet where many pulses have either no recorded signal photons at all, or signal photons that are widely spread in vertical direction.

The gray dots in the figure are background photons, time-tagged within the range window. The photon events are classified into signal and background photons, by dividing the range window into bins and counting the photon events in each bin. A decision is made based on the number and distribution of the photon events in each bin (Neumann et al., submitted). Signal photons are represented by blue dots. The upper panel shows a relatively smooth ice surface, manifest by the narrow vertical distribution of the signal photons $(\sim 1 \mathrm{~m})$, simulated under good atmospheric conditions and high reflectance. The lower panel is nearly the opposite: it is over a very rugged ice surface, assuming poor atmospheric conditions and low reflectance. The distribution of signal photons is now much broader $(\sim 12 \mathrm{~m})$ and several pulses have no signal photons at all.

We now briefly describe how to extract surface photons from the original photon cloud. The original photon cloud has a label assigned to every photon event within the range window that expresses the likelyhood of being reflected by the Earth's surface. A closer look at the distribution of signal photons reveals a band-shaped pattern. The upper panel of Fig. 3 shows a $300 \mathrm{~m}$ long segment of signal photons over a rugged ice surface, simulated with a low atmospheric transmission rate and poor reflectance properties. It is the same location as the photon cloud shown in the lower panel of Fig. 2, except a different repeat cycle is selected. The maximum vertical spread of signal photons in the left half of the left panel is about $12 \mathrm{~m}$ with a random photon distribution that makes it next to impossible to discern a surface. To make the graphical representation in Fig. 3 more readable, the vertical dimension is exaggerated ten times.

The objective of the filtering process is to eliminate isolated signal photons whose distances to neighbors exceed a threshold value. To achieve this goal we superimpose a regular grid structure on the domain of the signal photons. The grid size should be chosen such that grid cells within the cluster will contain enough signal photons. Based on experience we have selected a grid size of $10 \mathrm{~m}$ along track and $10 \mathrm{~cm}$ in vertical direction. Every grid cell contains the number of signal photons whose locations fall within the cell. The higher that number the more densely packed are the signal photons. We now eliminate cells with low density numbers. Assume, for example, a cell that only contains one signal photon. We can safely eliminate this cell from further consideration because that signal photon has no neighbors in an area of $10 \mathrm{~m}$ by $0.1 \mathrm{~m}$.

The lower panel of Fig. 3 shows the result of the thinning process. The blue dots are the surviving signal photons and red dots indicate the true surface, known from the simulation (intersection of photons with DEM). We notice a good agreement between the filtered signal photons and the true surface, given the fact that it is over a very rugged area.

\subsection{Calculation of time series of surface elevation changes}

We have originally developed SERAC (Surface Elevation Reconstruction And Change detection) for detecting surface elevation changes from ICESat laser altimetry observations
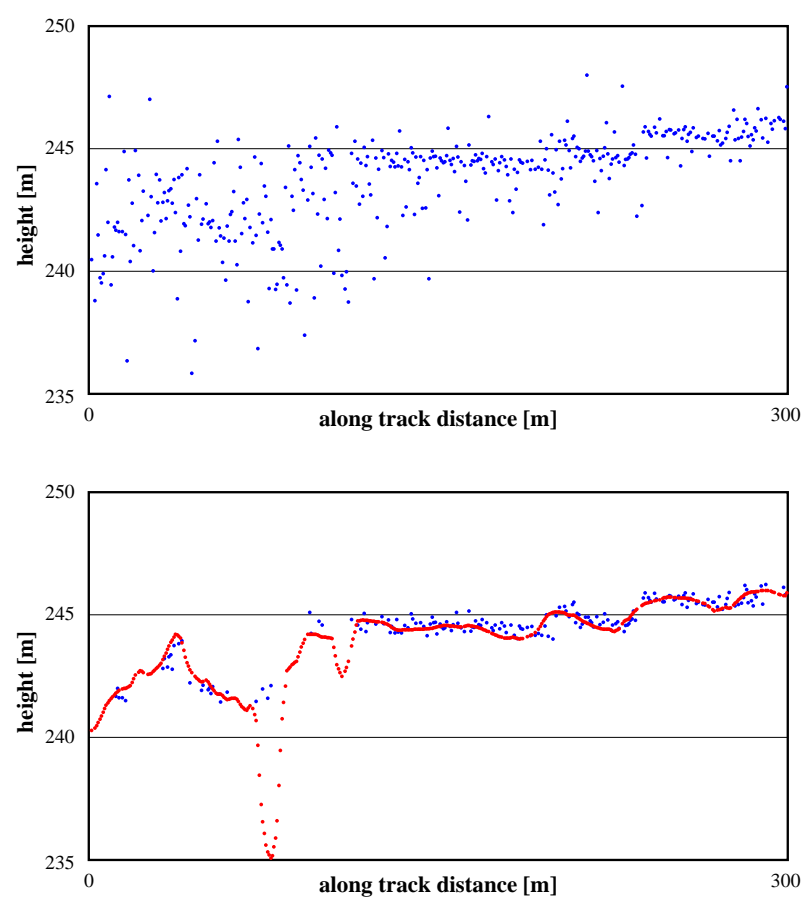

Figure 3: The upper panel shows the signal photons of a $300 \mathrm{~m}$ long segment. The distribution of signal photons in the left half of the panel vividly demonstrates the difficulty to discern the real surface. This is different in the right half where the photons are closely clustered around the surface. The lower panel shows the result of filtering with the signal photons clustered along a much narrower band. The red dots show the true surface and the good agreement between blue and red dots show the success of the filtering algorithms.

(Schenk, Csatho, 2012). Over time we have extended SERAC several times, for example by including data from other sensors, such as NASA's ATM (Airborne Topographic Mapper) and LVIS (Laser Vegetation Imaging Sensor). More recently, we have extended SERAC to include observations from ICESat-2. Fusing data from different sensors offers several advantages: the duration of time series may increase and/or the temporal sampling becomes denser.

We combined the simulated ICESat-2 data with ICESat (2003-09), ATM (2002, 2009, 2011, 2014 and 2016), and LVIS (2011 and 2015) observations to generate 14-year long time series of surface elevation change on the PIne Island Glacier, West Antarctica to demonstrate the fusion capabilities of SERAC. The data included GLAH12 level-2 (L2) Antarctic and Greenland Ice Sheet Altimetry Data, Version 34, IceBridge ATM L1B Elevations, and IceBridge LVIS L2 Geolocated Surface Elevation Product, Version 1, depicting ice sheet elevations for each ICESat, ATM and LVIS laser altimetry footprint, respectively (Zwally et al., 2014, Studinger, 2013, updated 2018, Blair, Hofton, 2010, updated 2018).

Fig. 4 shows two examples of these time series with data from ICESat, ATM, LVIS and the first time epoch of the simulated ICESat-2 data. The figure in the upper panel shows a thinning of almost 50 meters near the grounding line of the Pine Island Glacier. The pattern of elevation change indicates that rapid thinning started in 2004, consistent with earlier radar altimetry results in (Wingham et al., 2009).

Thinning rates rapidly decreased after 2011 as the glacier reached a new equilibrium by 2014 . At the second location (lower panel), further inland and toward the shear margin, 
thinning has started later, was less rapid (only 30 meters in 14 years) and has been still significant in 2016. This behavior is consistent with thinning initiated near the grounding line and diffusing upstream, such as shown on the Jakobshavn glacier in Greenland (Csatho et al., 2014).
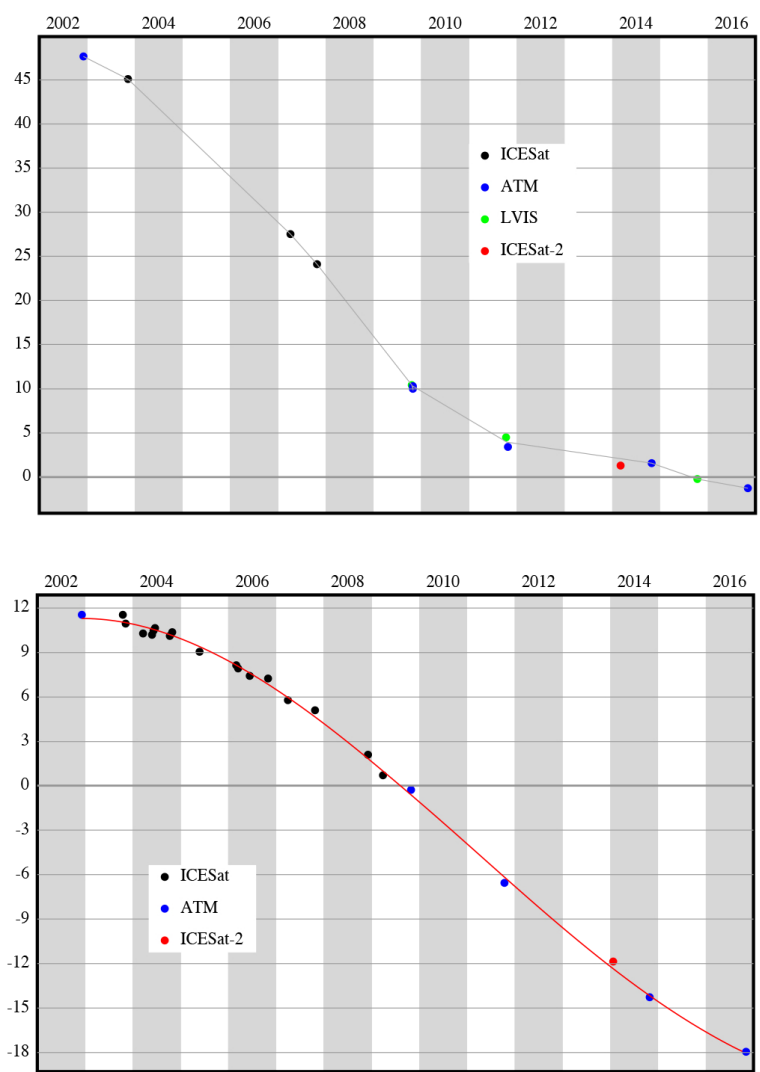

Figure 4: Elevation change time series from airborne (ATM, LVIS), spaceborne (ICESat) and simulated spaceborne (ICESat-2) laser altimetry data. The red dot marks the first pass of the simulated ICESat-2 data. Upper panel show elevation change near the grounding line, while lower panel refers to a location further inland.

\section{CONCLUSIONS}

In this study we have provided an overview of the newly launched ICESat-2 system with its unique photon-counting laser altimetry system ATLAS. We also highlighted two applications, namely surface extraction from the photon cloud and surface change detection. ICESat-2 offers two data products, ATL03 and ATL06, both suitable for computing time series. We have used data product ATL03 for the experiments presented here. ATL03 is the only data product that contains original ATLAS observations. Later data products have quantities derived from ATL03. For example, ATL06 has computed laser point observations at intervals of $20 \mathrm{~m}$ along track. Although this is advantages for certain applications we prefer using ATL03 because SERAC essentially computes the parameters of a 3-D model of the real surface. It is important to remember that the shape parameters of the modelled surface are simultaneously computed from all time epochs. In the light of this we conclude that a denser, more evenly spaced set of laser point observation is preferable. Moreover, the larger the redundancy (number of observations minus number of unknowns) the more robust the result.

\section{ACKNOWLEDGEMENT}

Worldview-2 DEMs were provided by the Polar Geospatial Center at the University of Minnesota, St. Paul, MN. Research was funded by NASA's ICESat-2 project, grant number 80NSSC18K1289.

\section{REFERENCES}

Blair, J.B., Hofton, M., 2010, updated 2018. IceBridge LVIS L2 Geolocated Surface Elevation Product, Version 1. National Snow and Ice Data Center Distributed Active Archive Center, Boulder, Colorado USA, doi: https://doi.org/10.5067/OIKFGJNBM6OO.

Brunt, K.M., Neumann, T.A., Amundson, J.M., Kavanaugh, J.L., Moussavi, M.S., Walsh, K.M., Cook, W.B., Markus, T., 2016. MABEL photon-counting laser altimetry data in Alaska for ICESat-2 simulations and development. The Cryosphere, $10,1707-1719$.

Csatho, B.M., Schenk, A.F., van der Veen, C.J., Babonis, G., Duncan, K., Rezvanbehbahani, S., Van Den Broeke, M.R., Simonsen, S.B., Nagarajan, S., Van Angelen, J.H., 2014. Laser altimetry reveals complex pattern of Greenland Ice Sheet dynamics. Proceedings of the National Academy of Sciences, $111,18478-18483$.

Enderlin, E.M., Howat, I.M., Jeong, S., Noh, M-J., Angelen, J.H., Broeke, M.R., 2014. An improved mass budget for the Greenland ice sheet. Geophysical Research Letters, 41, 866-872.

Herzfeld, U.C., Trantow, T.M., Harding, D., Dabney, P.W., 2017. Surface-Height Determination of Crevassed Glaciers-Mathematical Principles of an Autoadaptive Density-Dimension Algorithm and Validation Using ICESat-2 Simulator (SIMPL) Data. Geoscience and Remote Sensing, IEEE Transactions on, 55, 1874-1896.

Markus, T., Neumann, T., Martino, A., Abdalati, W., Brunt, K., Csatho, B., Farrell, S., Fricker, H., Gardner, A., Harding, D., Jasinski, M., Kwok, R., Magruder, L., Lubin, D., Luthcke, S., Morison, J., Nelson, R., Neuenschwander, A., Palm, S., Popescu, S., Shum, C.K., Schutz, B.E., Smith, B., Yang, Y.K., Zwally, J., 2017. The Ice, Cloud, and land Elevation Satellite-2 (ICESat-2): Science requirements, concept, and implementation. ISPRS J. Photogramm. Rem. Sens., 260-273.

Neumann, T., Martino, A.J., Markus, T., Bae, S., Bock, M., Brenner, A.C., Brunt, K.M., Cavanaugh, J.F., Fernandes, S.T., Hancock, D.W., Harbeck, K., Lee, J.E., Kurtz, N.T., Luers, P.J., Luthcke, S.B., Magruder, L., Pennington, T.A., Ramos-Izquierdo, L.A., Rebold, T., Skoog, J., Thomas, T.C., submitted. The Ice, Cloud, and land Elevation Satellite 2 Mission: A Global Geolocated Photon Product. Remote Sensing of Environment.

Pattyn, F., Ritz, C., Hanna, E., Asay-Davis, X., DeConto, R., Durand, G., Favier, L., Fettweis, X., Goelzer, H., Golledge, N.R., Munneke, P.K., Lenaerts, J.T.M., Nowicki, S., Payne, A.J., Robinson, A., Seroussi, H., Trusel, L.D., van den Broeke, M., 2018. The Greenland and Antarctic ice sheets under $1.5^{\circ} \mathrm{C}$ global warming. Nature Climate Change, 41, 1-9. 
Schenk, T., Csatho, B., 2012. A New Methodology for Detecting Ice Sheet Surface Elevation Changes From Laser Altimetry Data. IEEE Transactions on Geoscience and Remote Sensing, 3302-3316.

Schenk, T., Csatho, B.M., Smith, B.E., Neumann, T., submitted. Time series of surface elevation changes from simulated ICESat-2 data. ISPRS Journal of Photogrammetry and Remote Sensing.

Shean, D.E., Alexandrov, O., Moratto, Z.M., Smith, B.E., Joughin, I.R., Porter, C., Morin, P., 2016. An automated, open-source pipeline for mass production of digital elevation models (DEMs) from very-high-resolution commercial stereo satellite imagery. ISPRS J. Photogramm. Rem. Sens., 101-107.

Studinger, M., 2013, updated 2018. IceBridge ATM L1B Elevation and Return Strength, Version 2. National Snow and Ice Data Center Distributed Active Archive Center, Boulder, Colorado USA, doi: https://doi.org/10.5067/19SIM5TXKPGT.

The IMBIE team, 2018. Mass balance of the Antarctic Ice Sheet from 1992 to 2017. Nature, 558, 219-222.

van Den Broeke, M.R., Enderlin, E.M., Howat, I.M., Kuipers Munneke, P., Noël, B.P.Y., Van De Berg, W.J., Van Meijgaard, E., Wouters, B., 2016. On the recent contribution of the Greenland ice sheet to sea level change. The Cryosphere, 10, 1933-1946.

Wingham, D.J., Wallis, D.W., Shepherd, A., 2009. Spatial and temporal evolution of Pine Island Glacier thinning, 1995-2006. Geophysical Research Letters, 36, L17501.

Zwally, H. J., Schutz, R., Hancock, D., Dimarzio, J., 2014. GLAS/ICESat L2 Antarctic and Greenland Ice Sheet Altimetry Data (HDF5), Version 34. National Snow and Ice Data Center Distributed Active Archive Center, Boulder, Colorado USA, doi: https://doi.org/10.5067/ICESAT/GLAS/DATA209.

Zwally, H.J., Schutz, B., Abdalati, W., Abshire, J., Bentley, C., Brenner, A., Bufton, J., Dezio, J., Hancock, D., Harding, D., Herring, T., Minster, B., Quinn, K., Palm, S., Spinhirne, J., Thomas, R., 2002. ICESat's laser measurements of polar ice, atmosphere, ocean, and land. Journal of Geodynamics, 34, 405-445. 